\title{
The search for the most eco-efficient strategies for sustainable housing construction; Dutch lessons
}

Gerda Klunder

Delft University of Technology

OTB Research Institute for Housing, Urban and Mobility Studies

P.O. Box 5030

2600 GA Delft

The Netherlands

E-mail: g.klunder@otb.tudelft.nl

Phone: +31-15 2786341

Fax: +31-15 2783450 



\title{
The search for the most eco-efficient strategies for sustainable housing construction; Dutch lessons
}

\begin{abstract}
Although sustainability plays an increasingly important role in common building practice, there is very little known about the environmental benefits of sustainable housing construction. This paper presents a framework for the search for the most eco-efficient strategies for sustainable housing construction and discusses the environmental benefits of Dutch sustainable housing construction. Two questions are answered: which goals regarding the environmental benefits of Dutch sustainable housing construction are currently feasible and what are the most eco-efficient strategies to further improve the environmental performance of housing? Environmental benefits are calculated by means of sets of measures composed by confronting priorities for reduction of the environmental impacts of houses with seven strategies for sustainable housing construction. For the calculations Eco-Quantum is used. A traditionally built terraced house is used as a reference point. It turns out that goals such as 'Factor 4' or 'Factor 20' are still far from being achieved and that the prolongation of life spans and improvement of reusability are the most eco-efficient strategies. However, other strategies also need to be applied, because these two strategies carry large uncertainties. Sustainable housing construction may not be enough in itself to meet very high targets. Reflection on our way of living is also required.
\end{abstract}

Keywords: eco-efficiency, Eco-Quantum, environmental benefits, environmental impacts, environmental performance, housing, LCA, sustainability, the Netherlands

\section{Introduction}

In recent years, a growing number of sustainable building projects have been realised and sustainable building is increasingly becoming part of common building practice. Plenty of measures are known for reducing the environmental impacts of building. There is, however, very little knowledge on the magnitude of the environmental benefits that these measures yield. This also means that we barely know which goals can be met and what the best solutions are to meet them. The aim of this paper is to present a framework for the search for the most eco-efficient strategies for sustainable housing construction and to discuss the environmental benefits of Dutch sustainable housing construction. Two questions are answered: which goals regarding the environmental benefits of Dutch sustainable housing construction are currently feasible and what are the most eco-efficient strategies to further improve the environmental performance of housing? 
Section 2 deals with definitions, measurements and goals with regard to sustainable housing construction. In section 3 the framework to find the most eco-efficient strategies is presented. Section 4 is concerned with the empirical results of the environmental benefits of Dutch sustainable housing construction and the most ecoefficient strategies to further improve the environmental performance of housing. In section 5 conclusions are drawn. Section 6 contains a discussion.

\section{Sustainable housing construction: definitions, measurements and goals}

\subsection{Definitions}

The report Our Common Future (WCED, 1987) has led to a world-wide notion of the concept of sustainable development, defined as a "development which meets the needs of the present without compromising the ability of future generations to meet their own needs." The Commission not only observed that environmental problems need to be addressed, but also social problems, such as inequity, poverty, non-prosperity and the violation of human rights, that are related to explosive population growth and the enormous expansion of environmental harms caused by human activities. According to the Commission, solving these problems requires global economic growth whilst respecting ecological constraints.

It is difficult to handle the strategic concept of sustainable development with respect to operational decisions for a sustainable built environment. The ecological conditions strategy (Tjallingii, 1996) offers more opportunities to do so. It does not focus on future results, but on present steps being taken towards sustainability by providing guiding principles. Three dimensions of sustainability are distinguished: the durable diversity of areas, the sustained use of resources and the sustained involvement of actors. These dimensions are indicated in short as areas, flows and actors.

Nonetheless, narrowing the scope from the built environment towards buildings and building components requires sustainability to be translated as the responsible management of flows. After all, on the scale of the building and its components, areas and actors are of minor relevance compared to the scale of the neighbourhood or the city. The definition of sustainable construction, according to the Dutch Ministry of Housing, Spatial Planning and the Environment (1990), confirms this. The ministry explains sustainable construction as directed towards the reduction of the environmental and health impacts consequent to construction, buildings and the built environment. The focus on sustainable housing construction implies a perspective of flows. From this viewpoint, a sustainable house is characterised by the minimisation of the environmental impacts of material use, energy consumption and water consumption during the whole service life of the building.

\subsection{Measurements}

Life Cycle Assessment or LCA is a widely accepted method to assess environmental impacts. It is a method for the analysis of the environmental burden of products (goods 
and services) from cradle to grave, including extraction of raw materials, production of materials, product parts and products and discard, either by recycling, reuse or final disposal (Guinée et al., 2002). It is defined as the "compilation and evaluation of the inputs, outputs and potential environmental impacts of a product system throughout its life cycle" (ISO, 1997). The product system is the total system of processes needed for the product, which in this case is a house. Inputs and outputs are the materials and energy which enter and leave the product system.

The framework for LCA, which has been internationally agreed upon, distinguishes four phases (ISO, 1997).

1. The goal and scope of an LCA have to be clearly defined and geared to the intended use. An important part of the goal and scope definition is the determination of the functional unit, which is the quantified function of the product system under study. The functional unit serves as a reference unit in an LCA, e.g. $\mathrm{x} \mathrm{m}^{2}$ floor system with a supporting power of $\mathrm{x} \mathrm{N} / \mathrm{m}^{2}$ during $\mathrm{x}$ years.

2. Inventory analysis is the second phase of an LCA, in which the inputs and outputs of the product system are compiled and quantified, including natural resources and emissions to air, water and soil.

3. The third phase is concerned with the understanding and evaluation of the magnitude and significance of the potential environmental impacts of the product system. Impact assessment encompasses assignment of inventory data to impact categories (classification), modelling of inventory data within impact categories (characterisation) and, only if useful, aggregation of the results (weighing). Examples of impact categories are depletion of raw materials, ozone depletion, acidification and eutrophication.

4. Finally, the interpretation phase contains interpretation of the results of the inventory analysis and impact assessment in the light of the goal and scope definition in order to draw up conclusions and recommendations by means of completeness, sensitivity, consistency and other checks.

In many countries whole-building assessment tools have been developed or are being developed for the environmental assessment of housing, including Eco-Quantum in the Netherlands, Envest in the United Kingdom, EcoPro in Germany and ESCALE in France. These tools have been designed for use in the determination, analysis and improvement of the environmental performance of buildings (Knapen and Boonstra, 1999). Although these tools are based on the LCA methodology, building products and environmental data in databases connected to the tools are mostly country-specific. The applicability of tools in other countries is therefore very limited.

\subsection{Goals}

The ultimate goal for sustainable development is not to exceed the carrying capacity of the earth, as in the concept of environmental utilisation space (Opschoor and Weterings, 1994). Environmental utilisation means harvesting from the environment and putting waste into it. The environmental utilisation space stems from the regeneration and absorption abilities of the earth. These abilities will be smaller when environmental degradation is higher. Also the concept of the ecological footprint is based on the 
thought that we use no more resources than can be renewed and that we discharge no more waste than can be absorbed (Wackernagel and Rees, 1996). The ecological footprint is the land/water area required from nature to support the flows of energy and matter to and from any defined economy. According to this concept we would need at least three planets if everyone on earth lived like the average Canadian or American. Nevertheless the carrying capacity is not a steady state and the environment is a very complex system, so we do not know exactly what the earth can support.

Despite uncertainties about the extension of the carrying capacity, there is a general concern that we are going far beyond that point (e.g. Carson, 1962; Commoner, 1971; Meadows et al., 1972; Meadows et al., 1992). A manifold increase in environmental efficiency or eco-efficiency is needed for sustainable development. 'Factor 20' is a metaphor which refers to such leaps. Ehrlich and Ehrlich (1990) stated that the global environmental impact depends on the population size, the average prosperity per person and the environmental impact per unit of prosperity. So when a halving of the global environmental impact is wanted for the period from 1990 to 2040, a doubling of the population size by 2040 is assumed and average prosperity five times higher than in 1990 , then we have to reduce the environmental impact per unit of prosperity by a factor of 20. In the case of sustainable housing construction, the concept of eco-efficiency implies that a reduction in the environmental impacts of housing construction can be undone by trends such as an increase in the average size of houses, while the average number of persons per house is decreasing. These trends are not taken into account, so here the most eco-efficient strategies are defined as the strategies with the greatest potential of environmental benefits.

Weizsäcker et al. (1997) show several examples of technologies produced with only one-quarter of the energy and materials we presently use. This 'Factor 4' in resource productivity means that we can double wealth to solve the problems of poverty while halving resource use to return to an ecological balance on earth. It redirects the technological process from labour productivity to resource productivity in a profitable way. The examples reflect current possibilities for achieving a factor of 4 improvement in eco-efficiency.

Related to the 'factor thinking' Weaver et al. (2000) distinguish three innovation tracks with different time horizons and objectives. The first track is concerned with short-term optimisation or 'end-of-pipe measures'. This track has a time horizon of up to five years and results in the improvement of environmental efficiency by no more than a factor of 1.5. In the medium term, between five and ten years, a factor of from 1.5 to 4 is achievable. This demands environmental technology to be directed towards process or product-integrated technological improvement and reorganisation. A fundamental renewal of technologies and organisational arrangements is needed for an improvement of environmental efficiency by a factor of 4 up to 20. Sustainable technologies involve redefining existing development paths and initiating new ones, so breaking with the past. The time-horizon typically is twenty years or more.

It is clear, therefore, that incremental change is not enough to achieve sustainable development; rather it is renewed technological development that is essential. The 
power of 'Factor 20' lies in the encouragement of long-term thinking with a very high ambition level. Nevertheless, it is not completely clear what the factor does address. For example, Reijnders (1998) wonders what the factor of X refers to, whether it makes societal sense, whether improvement of technology is sufficient and how to implement 'Factor X' technology.

\section{Framework for the search}

Summarising the discussion on definitions, measurements and goals, sustainable housing construction is defined as reducing the environmental impacts of material use, energy consumption and water consumption. The environmental impacts of traditional as well as sustainable housing construction can be determined by LCA. Environmental benefits can be derived from that and compared to 'Factor $\mathrm{X}$ ' goals. The framework for the search for the most eco-efficient strategies for sustainable housing construction comprises four steps (see Figure 1).

\section{Figure 1. Research design}

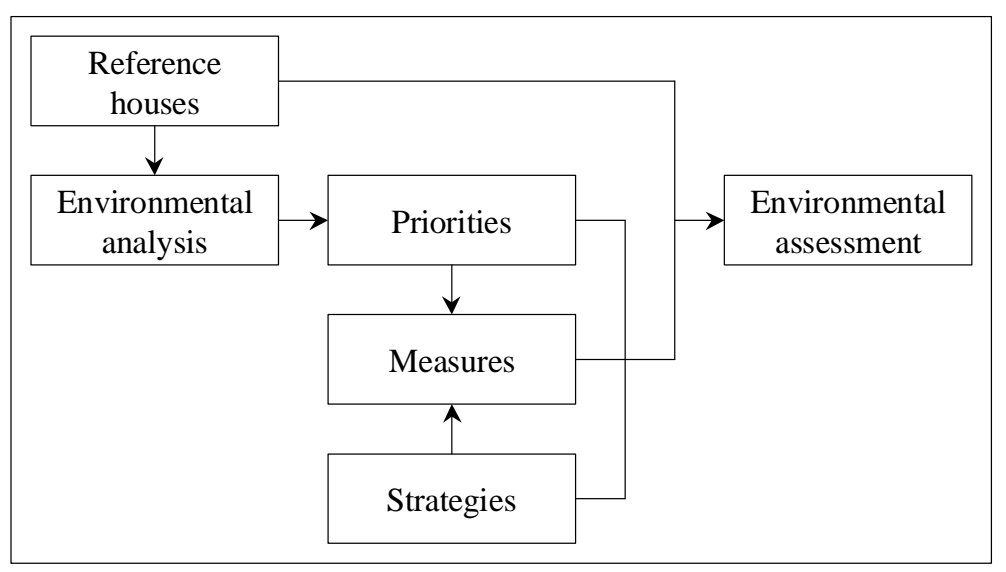

1. Selection of reference houses

To be able to compare sustainable housing with traditional housing, reference houses were selected. Three types of houses represent current Dutch housing construction: the terraced house, the semi-detached house and the gallery apartment (Novem, 1999a). Table 1 gives an overview of the most important construction and installation characteristics of the terraced house ${ }^{1}$.

1 These characteristics were used to determine priorities for the reduction of the environmental impacts of housing construction (step 2). In the meantime energy requirements in the Dutch Building Decree were strengthened. The mechanical ventilation system was replaced by a balanced ventilation system with heat recovery and the combined boiler for heating and hot water became more efficient, up to $107 \%$ (Novem, 1999b). These adjusted characteristics were applied for the environmental assessment of measures (step 4). 
Table 1. Construction and installation characteristics of the reference house

\begin{tabular}{|c|c|}
\hline House component & Characteristics \\
\hline Foundation & concrete beams and piles \\
\hline Fronts & $\begin{array}{l}\text { inner leave of sand-lime brick, rock wool cavity insulation and outer leave of } \\
\text { masonry }\left(R_{c}=3.0 \mathrm{~m}^{2} \mathrm{~K} / \mathrm{W}\right) \text {, frames, windows }\left(\mathrm{U}=1.7 \mathrm{~W} / \mathrm{m}^{2} \mathrm{~K}\right) \text { and doors }(\mathrm{U}=3.4 \\
\left.\mathrm{W} / \mathrm{m}^{2} \mathrm{~K}\right) \text { of unstamped sustainable wood }{ }^{2}\end{array}$ \\
\hline Load-bearing walls & sand-lime brick \\
\hline Interior walls & plaster \\
\hline Floors & $\begin{array}{l}\text { ground floor of ribbed waffle slabs fitted with EPS insulation }\left(R_{c}=3.0 \mathrm{~m}^{2} \mathrm{~K} / \mathrm{W}\right) \\
\text { and storey floors of hollow-core slabs }\end{array}$ \\
\hline Roof & $\begin{array}{l}\text { wooden roof elements clad with unstamped multiplex, insulated with EPS } \\
\text { plates and covered with concrete tiles }\left(\mathrm{R}_{\mathrm{c}}=3.0 \mathrm{~m}^{2} \mathrm{~K} / \mathrm{W}\right)\end{array}$ \\
\hline Heating and hot water & low $\mathrm{NO}_{\mathrm{x}}$ combined boiler \\
\hline Ventilation & mechanical ventilation system \\
\hline
\end{tabular}

Explanation of abbreviations: $\mathrm{R}_{\mathrm{c}}$ : thermal resistance; $\mathrm{U}$ : heat transmission.

2. Determination of priorities for the reduction of the environmental impacts of housing construction

The reference houses were environmentally analysed with Eco-Quantum to determine the priorities for reduction of the environmental impacts of housing construction. The major contributors to the environmental burden of material use, energy consumption and water consumption of Dutch traditional housing construction were established. All other contributors were subsequently not considered. The advantage is that sustainable measures have to be investigated for only some of the components. Nevertheless improvements that are easy to accomplish still must be implemented. The broad application of small improvements can also yield considerable environmental benefits.

3. Identification of strategies for sustainable housing construction

Strategies instead of single measures were chosen as the unit of the environmental analyses, so significant results could be gained despite method and data uncertainties ${ }^{3}$. By examining strategies and priorities sets of measures were chosen for environmental assessment.

Four strategies were distinguished for sustainable material use (Blaauw, 2001): dematerialisation, material substitution, prolongation of service lives and improvement of reusability. Dematerialisation refers to minimisation of the size of the flow of materials in the building industry. Material substitution is directed towards the reduction of the environmental impacts per unit of material throughout the service life. An extended service life means that the environmental impacts per functional unit decrease, because the environmental impacts are spread over a longer period of time. The

2 To be understood as a sustainability category, and not to be confused with sustainably produced wood. In the latter case we speak of stamped wood.

3 The strategies only refer to sustainable material use and sustainable energy consumption, because water consumption does not belong to the major contributors determined in the previous step. 
improvement of reusability supports the use of building components and materials in a subsequent life cycle instead of dumping or combustion.

The trias energetica presents three steps to achieving sustainable energy consumption (Duijvestein, 1998): reduction of energy losses, use of infinite sources and clean and efficient use of finite sources. The reduction of energy losses involves measures which contribute to a low energy need. Renewable energy in housing notably means solar energy and warmth from the soil, water and air. Finally, the use of efficient techniques implies supplying the remaining energy need as efficiently as possible.

\section{Environmental assessment of sets of measures}

Eco-Quantum was used for calculations on the environmental benefits of sustainable housing construction. The Dutch tool Eco-Quantum is a tool for LCA of houses, meant for architects, clients and municipal councils where its uses include optimising designs, benchmarking and policy framing (Mak et al., 1999).

The tool conducts an LCA of the flows of materials, energy and water during the service life. The flow of materials includes the use of materials for construction, maintenance and the replacement of all house components, including material-embodied energy. The flows of energy and water comprise energy consumption and water consumption respectively in the occupancy phase of the house. A standard service life of 75 years was assumed. Twelve impact categories can be analysed with Eco-Quantum: depletion of raw materials, depletion of fuels, global warming, ozone depletion, photo-oxidant formation, acidification, eutrophication, human toxicity, ecological toxicity, energy consumption, non-hazardous waste and hazardous waste ${ }^{4}$.

The assessments were conducted on the level of these impact categories. Weighting factors were not applied to come to a single indicator, because these involve political choices and policy decisions. However the importance given to each environmental impact category has a large influence on the ultimate choice of one or more strategies for sustainable housing construction.

\section{Environmental benefits of Dutch sustainable housing construction}

\subsection{Priorities for reduction of environmental impacts}

Not surprisingly, the flows of materials, energy and water increases according to the dwelling size, as is shown in Table 2. On the other hand the type of house also creates clear differences. In terms of the floor area the semi-detached house comes out worst in terms of energy flow, while the gallery apartment comes out worst in terms of materials.

The latter three are not really impact categories, but pressure indicators (MegaJoules and kilograms). Although such pressure indicators have a strongly recognisable function, this paper does not include them to avoid double counting. However, the pressure indicators were included in the environmental analysis of the reference houses (step 2). 
Table 2. Absolute amount of flows in the reference houses

\begin{tabular}{lrrrrrr}
\hline Flow & \multicolumn{2}{c}{ Terraced dwelling } & \multicolumn{2}{c}{ Semi-detached dwelling } & \multicolumn{2}{r}{ Gallery flat } \\
& Total & Per m & Total & Per m & Total & Per m $^{2}$ \\
\hline Materials & 205 ton & 1.9 ton & 254 ton & 1.9 ton & 153 ton & 2.0 ton \\
Energy & $4,157 \mathrm{GJ}$ & $37.4 \mathrm{GJ}$ & $5,252 \mathrm{GJ}$ & $39.2 \mathrm{GJ}$ & $2,680 \mathrm{GJ}$ & 35.7 GJ \\
Water & $6,772 \mathrm{~m}^{3}$ & $61.0 \mathrm{~m}^{3}$ & $10,847 \mathrm{~m}^{3}$ & $81.0 \mathrm{~m}^{3}$ & $4,110 \mathrm{~m}^{3}$ & $54.8 \mathrm{~m}^{3}$ \\
\hline
\end{tabular}

Figure 2 shows the distribution of the environmental impacts of the terraced house between material use, energy consumption and water consumption. The total environmental impacts are set at $100 \%$. It can be seen that both material use and energy consumption contribute more than 50\% to three environmental impact categories. Water consumption only has a notable share of one environmental impact category. Although the housing typology also influences the environmental impacts, it appears that there are also great similarities between material use, energy consumption and water consumption. Therefore the same priorities for reducing the environmental impacts can apply to all reference houses.

Figure 2. Distribution among material use, energy consumption and water consumption of the environmental impacts of the terraced house

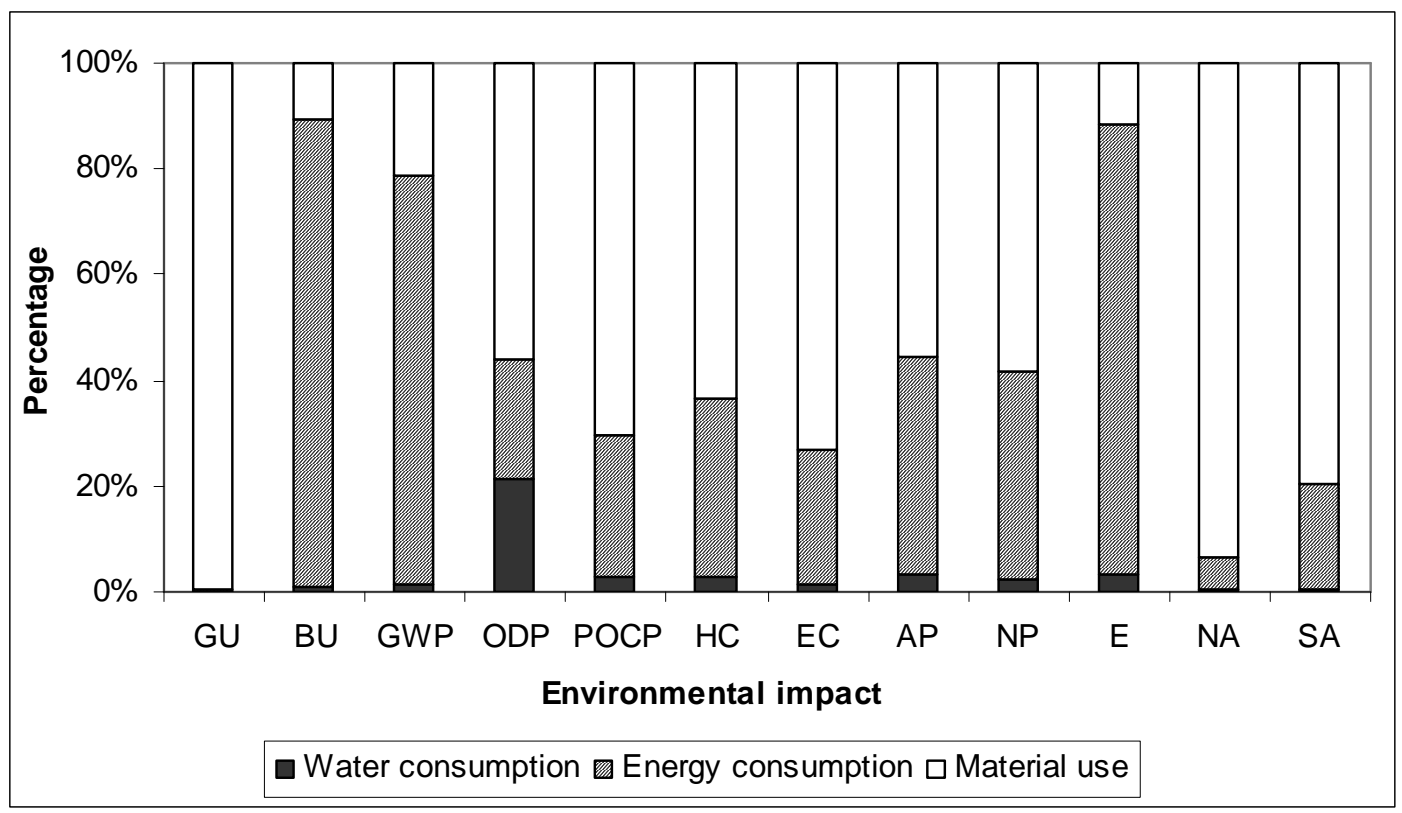

Source: Eco-Quantum 1.00. Explanation of abbreviations: GU: depletion of raw materials; BU: depletion of fuels; GWP: global warming; ODP: ozone depletion; POCP: photo-oxidant formation; HC: human toxicity; EC: ecological toxicity; AP: acidification; NP: eutrophication; E: energy consumption; NA: nonhazardous waste and SA: hazardous waste.

Priorities on material use mainly relate to house components that involve large quantities of materials. These are the foundation beams, outer leaves, window frames, 
glazing, interior walls, load-bearing walls, ground floor, storey floors, floor overlays, roof construction and heat-generation installation. There are also some materials which are very environmentally unfriendly regarding one or a few environmental impacts, including lead, copper and bitumen.

Priorities on energy consumption relate to all energy functions: space heating, hot tap water, lighting, ventilation and auxiliary energy. Although only a quarter of the energy consumption is electricity and three-quarters of the energy consumption is related to the gas-fired functions, both belong to the priorities. It appeared that the energy carrier is of great importance in assessing the environmental impacts.

No priorities relate to water consumption, because the environmental impacts of water consumption are as good as negligible compared to the environmental impacts of material use and energy consumption ${ }^{5}$.

\subsection{Environmental assessment of sets of measures}

By examining the priorities and the seven strategies for sustainable housing construction, sets of measures were composed for each housing type. To circumvent an irrelevant overload of figures as well as the notion that housing typology is of minor importance in this study, from now on this paper focuses on the terraced house, as the most common and desired house in the Netherlands.

The sets of measures for sustainable material use relate to current subjects of debate. For dematerialisation, $10 \%$ smaller dimensions of the load-bearing structure were assumed. This is contrary to flexible housing construction, which often means that more materials are needed in the construction phase. For material substitution, renewable materials as well as plastic replacements for lead and copper were a set of measures. This reflects the dilemma between more environmentally sound materials with short service lives (e.g. renewable materials) and less environmentally sound materials with long service lives (e.g. heavy metals). Prolongation of service lives might concern both the service life of the house and the service life of its components. A prolongation of 15 years of the house was studied. The service life of components with a major influence on the environmental impacts was also prolonged by five years. Finally improvement of reusability is possible for the foundation and the interior walls at present. Comparable with the dilemma earlier mentioned the question is whether application of less environmentally sound materials with good recycling or reuse possibilities is a better option than environmentally sound materials with bad recycling or reuse possibilities.

The sets of measures for sustainable energy consumption consist of technologies which are often applied in Dutch sustainable housing construction. An increase in the thermal resistance of the building envelope and a decrease in the heat transmission of the glazing refer to the reduction of energy losses. The use of infinite sources in housing notably means solar energy, so thermal and photo-voltaic solar-energy systems were

5 It has to be mentioned that dehydration of areas is the most important environmental aspect involved with water consumption. This aspect is not taken into account in LCA. 
calculated. The use of finite sources was worked out as low-temperature space heating and high-efficiency ventilation.

Tables 3 and 4 present the results of the Eco-Quantum calculations on the environmental benefits of sustainable material use and sustainable energy consumption respectively. The figures represent the environmental benefits in percentages in comparison with the reference house. Negative values mean that a rise instead of a reduction of environmental impacts occurs. Empty cells mean that there are no significant changes $(<5 \%)$.

Table 3. Environmental benefits of sets of measures for sustainable material use applied to the terraced house

\begin{tabular}{|c|c|c|c|c|c|c|c|c|c|c|}
\hline & \multirow[t]{2}{*}{ Sets of measures } & \multirow[b]{2}{*}{ 己 } & \multicolumn{8}{|c|}{ Environmental benefits in percentages } \\
\hline & & & $\stackrel{\bullet}{\bullet}$ & $\sum_{0}^{0}$ & $\hat{0}$ & 仓̊ & $\stackrel{U}{U}$ & $\underset{I}{\bigcup}$ & \& & z \\
\hline M1 & $10 \%$ smaller dimensions of load-bearing structure & & & & & & & & & \\
\hline M2a & renewable materials: timber-frame construction & & & 5 & 8 & & & & -5 & -6 \\
\hline M2b & plastics instead of lead and copper & 54 & & & & & 14 & 47 & & \\
\hline M3a & 90 years service life of house instead of 75 years & 17 & 17 & 18 & 20 & 19 & 19 & 18 & 19 & 19 \\
\hline M3b & 5 years prolongation of service life of components & 8 & & & & & & & & \\
\hline M4 & reuse of foundation and interior walls & 8 & & 5 & & 8 & 4 & & 5 & 5 \\
\hline
\end{tabular}

Table 4. Environmental benefits of sets of measures for sustainable energy consumption applied to the terraced house

\begin{tabular}{|c|c|c|c|c|c|c|c|c|c|c|}
\hline \multirow[t]{2}{*}{ 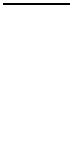 } & \multirow[t]{2}{*}{ Sets of measures } & \multirow[b]{2}{*}{ 己 } & \multirow[b]{2}{*}{$\stackrel{\bullet}{ }$} & \multirow[b]{2}{*}{$\sum_{0}^{2}$} & \multirow[b]{2}{*}{ ิิ } & \multicolumn{5}{|c|}{ Environmental impacts } \\
\hline & & & & & & 仓̊ & 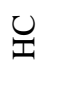 & UII & $\frac{2}{2}$ & Z \\
\hline E1 & $\begin{array}{l}\mathrm{R}_{\mathrm{c}}=4.0 \text { instead of } 3.0 \mathrm{~m}^{2} \mathrm{~K} / \mathrm{W}, \mathrm{U}_{\text {window }}=1.2 \text { instead } \\
\text { of } 1.7 \mathrm{~W} / \mathrm{m}^{2} \mathrm{~K}\end{array}$ & & 11 & 8 & & & & & & \\
\hline E2 & thermal and photo-voltaic solar-energy systems & -45 & 7 & 8 & -20 & & -6 & & -7 & \\
\hline E3 & $\begin{array}{l}\text { low-temperature space heating and high-efficiency } \\
\text { ventilation }\end{array}$ & & 5 & 5 & & & 6 & & 6 & 5 \\
\hline
\end{tabular}

Explanation of abbreviations: $\mathrm{R}_{\mathrm{c}}$ : thermal resistance; $\mathrm{U}$ : heat transmission.

The results led to the following findings.

- A $10 \%$ smaller dimension of the load-bearing structure does not result in significant environmental benefits. 
- Regarding application of renewable materials, environmental benefits in some environmental impacts go together with environmental disadvantages in others. Avoiding heavy metals pays off on particular impacts.

- The considerable environmental benefits of the prolongation of service lives of houses are a consequence of not needing a new house over the prolonged period. Prolongation of service lives of both houses and house components always results in a reduction in the environmental burden on all impacts. However, a five years prolongation of the service lives of the house components which exert a great influence on the environmental burden only leads to a significant decrease in the depletion of raw materials.

- Reuse of foundation and interior walls shows improvement on several environmental impacts.

- Insulation and efficient glazing causes environmental benefits on energy consumption with negligible environmental drawbacks on material use.

- Use of solar-energy systems leads to environmental drawbacks on four environmental impacts. This is due to the material use. The environmental benefits are comparable to insulation and efficient glazing.

- Application of low-temperature space heating and high-efficiency ventilation yields smaller environmental benefits in the depletion of fuels and global warming than the previous two sets of measures. To the contrary, larger environmental benefits on other impacts are achieved.

A closer look at the findings provides a better insight into the future perspectives of the strategies. A serious observation is that the strategy of using infinite energy sources saves fossil fuels, but the environmental impacts of the solar systems themselves are currently often ignored. The use of passive solar systems (e.g. orientation on the south) does not have these drawbacks. Thus more attention has to be paid to the material use of active solar systems (e.g. solar collectors and solar panels) to make the use of infinite sources a more promising strategy. Until now efficiency and comfort have been the main issues. There are plenty of options to improve the material performance, which are already under development, although not for environmental reasons. The strategy of material substitution is difficult, because it only occasionally yields positive consequences on all environmental impacts.

The strategies of dematerialisation, reduction of energy losses and the clean and efficient use of finite sources offer good perspectives at first, because these result in positive effects on certain environmental impacts with negligible negative effects on other environmental impacts. However, the advantages are limited since there comes a point where even more insulation or even smaller dimensions are not useful or desirable anymore. Therefore, the prolongation of service lives and improvement of reusability are needed to make a leap forward in the environmental performance of housing to achieve the target environmental benefits. For example, more materials are often initially involved in flexible houses, so to achieve the target environmental benefits the resident has to make use of the additional possibilities in functions or floor plans of the house. Another example concerns reuse: the question arises whether components which are suitable for reuse will really be reused in the future. This means that a very well reasoned approach is necessary. Due to the uncertainties involved with the strategies of 
prolongation of service lives and improvement of reusability, application of these strategies should be made together with other strategies.

\section{Conclusions and discussion}

Ambitions for sustainable technology development are often expressed in factors which refer to eco-efficiency. In the ecological conditions strategy eco-efficiency is concerned with the responsible management of flows. The factors can be calculated according to the LCA method. It turns out that goals such as factor 4 or factor 20 are still far from being achieved in Dutch sustainable housing construction, because the factors mean a reduction of the environmental impacts by $75 \%$ and $95 \%$ respectively, not including growing wealth. None of the environmental impacts show such reductions. Significant environmental benefits are achievable, but current Dutch sustainable construction practice does not go far enough to meet them. The prolongation of service lives and improvement of reusability seem the most eco-efficient strategies for sustainable housing construction. However, other strategies also need to be applied, because of the large uncertainties involved.

Although ambitious goals have not been realised yet it is very problematic to know how far away such ambitious goals are. For that we have to know what ' $\mathrm{X}$ ' should be to prevent exceeding the carrying capacity and what the 'Factor $\mathrm{X}$ ' refers to: new housing or the housing stock, single houses or neighbourhoods, districts and cities, or construction or living?

In 2000 the Dutch housing stock consisted of 6,588,100 houses. This stock will increase by a minimum of half a million houses up to 7.1 million in 2010 (Dutch Ministry of Housing, Spatial Planning and the Environment, 2000). This means that by 2010 new construction from 2000 on will amount to $13 \%$ of the housing stock. Although houses constructed in this ten-year period will form a considerable part of the future housing stock, there is a great potential in the present housing stock to improve the environmental performance of housing. Two million post-war houses have a far lower environmental quality than new houses. Moreover the number of houses in which improvements have to be realised is much larger.

Houses are just a small part of a neighbourhood, district or city. On these levels more solutions are possible to reduce the environmental impacts of housing. For example houses in a whole district can be heated by waste heat of industries. Such collective services in principle lead to larger environmental benefits than can be achieved in a single house. All scale levels are of equal importance and should be considered in an integral way. On higher scale levels conditions have to be created which make it possible to reach good environmental performance on lower scale levels. Sustainability of neighbourhoods or larger areas goes beyond flows. Also areas and factors have to be taken into account.

Finally big leaps in eco-efficiency, such as those illustrated by the 'Factor 20' metaphor cannot be achieved with sustainable housing construction or management. Sustainable 
development does not ask for decline, it demands fundamental renewal. Current innovation tracks mainly concern the optimisation and improvement of products and processes. System changes are necessary for such leaps or even changes in our set of norms and values. From that point of view it is not housing or urban planning that are subject to debate, but our way of living.

\section{References}

Blaauw, K. (2001) Duurzame woningbouw in perspectief, DUP Satellite, Delft.

Carson, R. (1962) Silent spring, Penguin Books, Harmondsworth.

Commoner, B. (1971) The closing circle; nature, man and technology, Knopf, New York.

Dutch Ministry of Housing, Spatial Planning and the Environment (1990) Nationaal milieubeleidsplan-plus; notitie instrumentarium + duurzaam bouwen, Sdu, Den Haag.

Dutch Ministry of Housing, Spatial Planning and the Environment (2000) Cijfers over wonen 2000/2001; feiten over mensen, wensen, wonen, Sdu, Den Haag.

Duijvestein, K. (1998) Ecologisch bouwen, Studiegroep StadsOntwerp \& Milieu, Faculteit Bouwkunde, Delft, $8^{\text {th }}$ print.

Ehrlich, P. and Ehrlich, A. (1990) The population explosion, Hutchinson, London.

Guinee, J.B., Gorree, M., Heijungs, R., Huppes, G., Klein, R., Koning, A. de, Oers, L. van, Wegener Sleeswijk, A., Sangwon, S., Udo de Haes, H.A., Bruijn, H. de, Duin R. van and Huijbregts, M.A.J. (2002) Handbook on life cycle assessment: an operational guide to the ISO standards, Kluwer Academic Publishers, Dordrecht.

International Organization for Standardization (ISO) (1997) Environmental management - Life cycle assessment - Principles and framework, ISO 14040: 1997, ISO, Geneva.

Knapen, M. and Boonstra, C. (1999) Milieubelasting van de Nederlandse referentiewoning berekend met instrumenten uit 13 landen, Bouwfysica, 11, 1, 35-38.

Mak, J.P., Anink, D., Kortman, J.G.M. and Gelinck, A.F. (1999) Eco-Quantum handleiding versie 1.00, Stuurgroep Experimenten Volkshuisvesting and Stichting Bouwresearch, Rotterdam.

Meadows, D.H., Meadows, D.L., Randers, J. and Behrens C.W. (1972) The limits to growth, Universe Books, New York. 
Meadows, D.H., Meadows, D.L. and Randers, J. (1992) Beyond the limits; global collapse or a sustainable future, Earthscan, London.

Nederlandse onderneming voor energie en milieu (Novem) (1999a) Referentiewoningen '98, Novem, Sittard.

Nederlandse onderneming voor energie en milieu (Novem) (1999b) Referentiewoningen '99, Novem, Sittard.

Opschoor, J.B. and Weterings, R. (1994) Environmental utilisation space: an introduction, Milieu, 9, 5, 198-205.

Reijnders, L. (1998) The factor X debate: setting targets for eco-efficiency, Journal of Industrial Ecology, 2, 1, 13-22.

Tjallingii, S.P. (1996) Ecological conditions; strategies and structures in environmental planning, Delft University of Technology, Delft.

Wackernagel, M., and W. Rees (1996) Our ecological footprint - reducing human impact on the earth, New Society Publishers, Gabriola Island.

Weaver, P., Jansen, L., Grootveld, G. van, Spiegel, E. van, and Vergragt, P. (2000) Sustainable technology development, Greenleaf Publishing, Sheffield.

World Commission of Environment and Development (1987) Our common future, Oxford University Press, Oxford.

Weizsäcker, E. von, Lovins, A.B. and Lovins, L.H. (1997) Factor four; doubling wealth - halving resource use, Earthscan, London. 